\title{
Significance of Additional Gastrectomy Including Endoscopic Submucosal Dissection Scar for Gastric Cancer
}

\author{
RYO ISHIDA ${ }^{1}$, SHINGO KANAJI ${ }^{1}$, RITSUKO MAEHARA ${ }^{2}$, HIROSHI HASEGAWA ${ }^{1}$, MASASHI YAMAMOTO ${ }^{1}$, \\ YOSHIKO MATSUDA ${ }^{1}$, KIMIHIRO YAMASHITA ${ }^{1}$, TAKERU MATSUDA ${ }^{1}$, TARO OSHIKIRI $^{1}$, \\ YASUO SUMI ${ }^{2}$, TETSU NAKAMURA ${ }^{1}$, SATOSHI SUZUKI ${ }^{1}$ and YOSHIHIRO KAKEJI ${ }^{1}$ \\ ${ }^{1}$ Division of Gastro-intestinal Surgery, Department of Surgery, \\ Kobe University Graduate School of Medicine, Kobe, Japan; \\ ${ }^{2}$ Kobe University International Clinical Cancer Research Center, Kobe, Japan
}

\begin{abstract}
Background/Aim: The aim of the study was to evaluate the necessity of gastrectomy including endoscopic submucosal dissection (ESD) scar with margin-negative early gastric cancer (EGC). Patients and Methods: We analyzed 83 patients with EGC who received additional gastrectomy after non-curative ESD and evaluated the risk factors for residual cancer $(R C)$ and lymph node ( $L N)$ metastasis. Results: In addition to positive ESD margin, ulceration was a risk factor for RC. Among cases with deep submucosal invasion (sm), 3 were diagnosed as having negative margins in ESD specimens, but the surgical specimens were positive for cancer. The rate of $L N$ metastasis was $12.0 \%$. There was no significant difference in LN metastasis between tumor characteristics. Conclusion: $L N$ dissection is recommended after non-curative ESD. Gastrectomy including the ESD scar should be performed not only for cases with positive margin in ESD, but also for cases with invasion deeper than sm2, even though the margin is negative.
\end{abstract}

Early gastric cancer (EGC) is defined as a neoplasm limited to the mucosa or the submucosa, regardless of regional lymph node (LN) metastasis (1). As diagnostic techniques have improved in the last years and the detection rate of small and early-stage gastric cancers has increased, the percentage of EGC is calculated to be approximately $50 \%$ of all detected cancers (2). Endoscopic submucosal dissection

Correspondence to: Dr. Shingo Kanaji, Division of Gastrointestinal Surgery, Department of Surgery, Kobe University Graduate School of Medicine, 7-5-2 Kusunoki-cho, Chuo-ku, Kobe 650-0017, Japan. Tel: +81 783825925, Fax: +81 783825939, e-mail: kanashin@med.kobeu.ac.jp

Key Words: Early gastric cancer, endoscopic submucosal dissection, additional surgery, residual cancer, lymph node metastasis.
(ESD) is a standard procedure for EGC because of its minimum invasion and satisfactory curability (3). However, few cases with residual cancer (RC) or recurrence following non-curative resection by ESD are still observed (4). Noncurative procedures are reported to account for 15.6-23.5\% of all endoscopic resections for EGC (4-7).

It has been reported that invasion deeper than sm2 (submucosal), undifferentiated histology, lympho-vascular invasion and ulceration are risk factors for LN metastasis, and additional radical gastrectomy with LN dissection has been generally recommended in these cases $(2,8-10)$. However, the necessity of gastrectomy including endoscopic submucosal dissection (ESD) scar with margin negative for early gastric cancer (EGC) remains unknown. Although it is rare, local recurrences may occur after complete resection in ESD, especially in patients with expanded lesions (11-14). Furthermore, some cases with RC in surgical specimens of additional gastrectomy have been reported, even though the ESD margin was negative (15).

In the present study, the risk factors for actual residual lesions and LN metastasis following additional gastrectomy after non-curative endoscopic resection were investigated.

\section{Patients and Methods}

We retrospectively evaluated 83 EGC patients who underwent additional gastrectomy following non-curative resection or RC after ESD at Kobe University from January 2008 to August 2016. The indication of ESD was decided according to the guideline for ESD that established by the Japanese Gastric Cancer Association (16). The resection was judged as curative when all of the following conditions were fulfilled: 1) en bloc or piecemeal resection with successful reconstruction, 2) negative lateral resection margins, 3) negative vertical margins, 4) no lymphovascular invasion. The following size and depth criteria also applied: 1) a tumor meeting the absolute indication for ESD (intra-mucosal tumor without ulcerative findings and of differentiated type with size $<2 \mathrm{~cm}$ ), 2) a tumor meeting the expanded indications for ESD (intra-mucosal tumor without ulcerative findings and of differentiated type with 
Table I. Clinicopathological features of the patients who received additional gastrectomy after ESD.

\begin{tabular}{|c|c|c|c|}
\hline & $\mathrm{n}=83(\%)$ & & $\mathrm{n}=83(\%)$ \\
\hline Age, median (range) & $69(44-85)$ & Tumor differentiation & \\
\hline Gender & & Differentiated & $52(63)$ \\
\hline Male/Female & $63(76) / 20(24)$ & Mixed & $26(31)$ \\
\hline Location & & Undifferentiated & $5(6)$ \\
\hline Upper & $21(25)$ & Depth & \\
\hline Middle & $40(48)$ & M & $9(11)$ \\
\hline Lower & $22(27)$ & SM1 & $20(24)$ \\
\hline Surgical procedure & & $>$ SM2 & $54(65)$ \\
\hline Open/Laparoscopy & $12(14) / 71(86)$ & UL & \\
\hline Total (OG/LG) & $3(25) / 9(13)$ & Positive/Negative & $39(47) / 44(53)$ \\
\hline Proximal (OG/LG) & $3(25) / 9(13)$ & Lymphatic invasion & \\
\hline Distal (OG/LG) & $6(50) / 53(74)$ & Positive/Negative & $33(40) / 50(60)$ \\
\hline Macroscopic type & & Vascular invasion & \\
\hline Elevated & $33(40)$ & Positive/Negative & $11(13) / 72(87)$ \\
\hline Flat & $2(2)$ & ESD margin positive & \\
\hline Depressed & $48(58)$ & Positive/Negative & $22(27) / 61(73)$ \\
\hline Tumor size & & Horizontal margin & \\
\hline$(\mathrm{mm})$, median (range) & $27(5-122)$ & Positive/Negative & $9(11) / 74(89)$ \\
\hline$\leq 20$ & $28(34)$ & Vertical margin & \\
\hline$>20, \leq 30$ & $21(25)$ & Positive/Negative & $17(20) / 66(80)$ \\
\hline$>30$ & $34(41)$ & & \\
\hline
\end{tabular}

ESD: Endoscopic submucosal dissection; OG: open gastrectomy; LG: laparoscopic gastrectomy; UL: ulceration.

size $>2 \mathrm{~cm}$, intra-mucosal tumor with ulcerative findings and of differentiated type with size $<3 \mathrm{~cm}$, intra-mucosal tumor without ulcerative findings and of undifferentiated type with size $<2 \mathrm{~cm}$, submucosal invasion $<500 \mu \mathrm{m}(\mathrm{sm} 1)$ and of differentiated type with size $<3 \mathrm{~cm})$.

Gastrectomy with D1+ LN dissection was performed for all 83 cases as an additional surgery.

Ethical approval. All procedures followed were in accordance with the ethical standards of the responsible committee on human experimentation (institutional and national) and with the Helsinki Declaration of 1964 and later versions.

Statistical analysis. Statistical analysis was performed with a chisquare test; a $p<0.05$ was considered significant. Statistical analyses were performed with JSTAT software program.

\section{Results}

Demographics and clinicopathological features of the patients who received additional gastrectomy after ESD. The demographics and clinicopathological features of the patients who received gastrectomy after ESD are summarized in Table I. The reasons for the additional surgery were as follows: submucosal invasion deeper than sm2 in 54 cases, undifferentiated or mixed type in 31 cases, differentiated shallow submucosal invasive cancer $(<\mathrm{sm} 1)>3 \mathrm{~cm}$ in diameter with ulceration in 13 cases, lymphatic invasion positive in 33 cases, vascular invasion positive in 11 cases.
Positive margin cases were vertical margin positive in 17 cases and lateral margin positive in 9 cases (4 cases overlapping) (Table I). The clinicopathological features were summarized according to the guideline in Figure 1. When cancer invasion was deeper than sm1, lymphovascular invasion was found to be increased, and when the invasion was at sm2 or deeper, positive ESD margins were found to be increased (Figure 1).

Open and laparoscopic gastrectomy were performed in 12 and 71 cases, respectively. The surgical procedures performed in the additional gastrectomies were as follows. Among the patients who received open gastrectomy, distal gastrectomy (DG) was performed in 6 cases, proximal gastrectomy (PG) in 3 cases and total gastrectomy (TG) in 3 cases. Among the patients who received laparoscopic gastrectomy, DG was performed in 53 cases, PG in 9 cases and TG in 9 cases (Table I). There was no recurrence or death during the 33 months of median follow-up.

$R C$ in surgical specimens. RC in surgical specimens were found in $14 \%$ (12/83 cases) of the cases that received additional gastrectomy after ESD. Ulceration and positive ESD margins, including both horizontal and vertical margins, were significantly recognized in surgical specimens of patients with RC (Table II). RC was found in $41 \%(9 / 22$ cases) of the cases with a positive margin in ESD specimens (Table II). On the other hand, cancer was detected in 5\% 


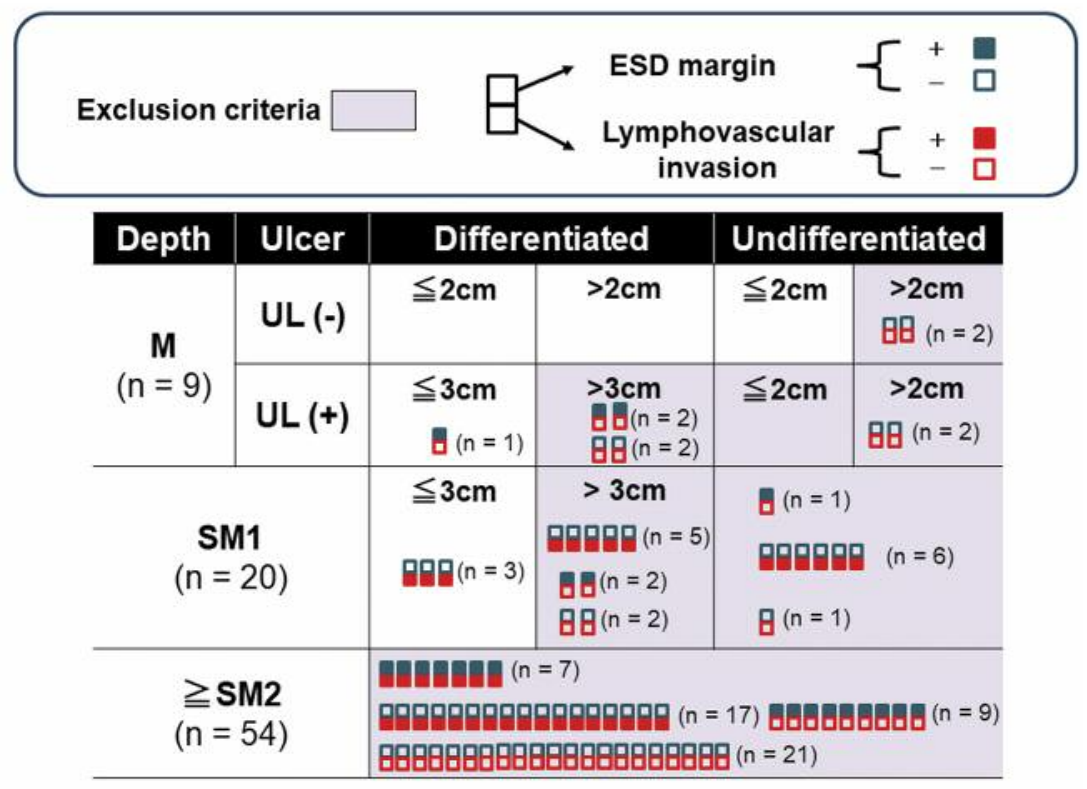

Figure 1. Clinicopathological features of the patients who received additional gastrectomy after ESD. The clinicopathological features were summarized according to the guidelines for ESD. The grey area shows exclusion criteria of ESD. ESD-positive margins are represented in bluefilled squares, and lymphovascular invasion is represented in red-filled squares.

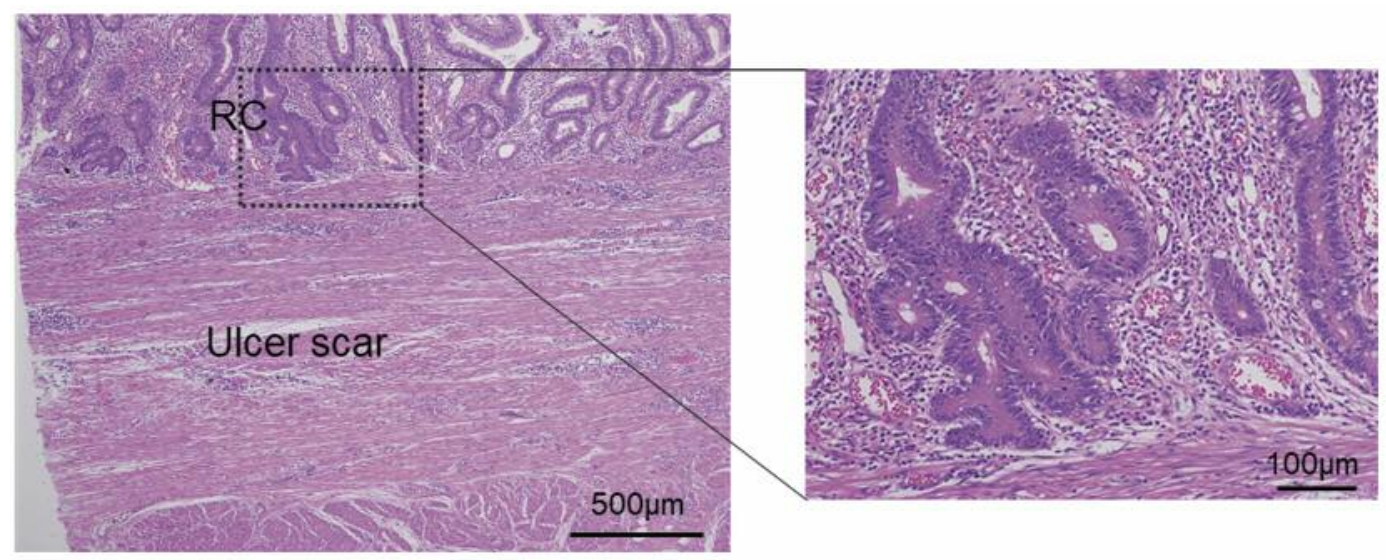

Figure 2. Histopathological examination of the gastrectomy specimen. Histopathological examination in case 2 showed that RC partially overlapped in the ESD ulcer scar (left: low magnification, right: high magnification, HE staining).

(3/61 cases) of the cases with a negative margin in ESD and all of them showed an invasion deeper than sm2 $(3 / 38$ cases), although there was no significant difference $(0 \%$ in cases with $<\mathrm{sm} 2$ vs. $8 \%$ in cases with $>\operatorname{sm} 2, p=0.167)$. The cases with a negative margin in ESD and positive in surgical specimens are summarized in Table III; the representative histopathological image is shown in Figure 2. Histopathological examination showed that RC partially overlapped in the ESD scar.
Clinicopathological background with or without $L N$ metastasis. LN metastases were found in $12.0 \%(10 / 83$ cases) of patients who received gastrectomy. The clinicopathological features of the patients with or without LN metastasis are summarized in Table IV. The rate of LN metastasis was $15 \%$ in cases with invasion deeper than sm2 ( $7 \%$ in cases with $<\operatorname{sm} 2, p=0.2907$ ), $16 \%$ in cases with undifferentiated histology (10\% in cases with differentiated type, $p=0.3779), 15 \%$ in cases with ulceration ( $9 \%$ in cases 
Table II. Clinicopathological background with or without residual cancer.

\begin{tabular}{|c|c|c|c|c|c|c|c|}
\hline & $\begin{array}{c}\mathrm{RC}(+) \\
\mathrm{n}=12(\%)\end{array}$ & $\begin{array}{c}\mathrm{RC}(-) \\
\mathrm{n}=71(\%)\end{array}$ & $p$-Value & & $\begin{array}{c}\mathrm{RC}(+) \\
\mathrm{n}=12(\%)\end{array}$ & $\begin{array}{c}\mathrm{RC}(-) \\
\mathrm{n}=71(\%)\end{array}$ & $p$-Value \\
\hline Age (years) & & & 0.20 & UL & & & 0.04 \\
\hline$<70$ & $4(10)$ & $38(90)$ & & Positive & $9(23)$ & $30(77)$ & \\
\hline$>70$ & $8(20)$ & $33(80)$ & & Negative & $3(7)$ & $41(93)$ & \\
\hline Gender & & & 0.42 & Lymphatic invasion & & & 0.62 \\
\hline Male & $8(13)$ & $55(87)$ & & Positive & $4(12)$ & $29(88)$ & \\
\hline Female & $4(20)$ & $16(80)$ & & Negative & $8(16)$ & $42(84)$ & \\
\hline Macroscopic type & & & 0.55 & Vascular invasion & & & 0.71 \\
\hline Non-depressed & $6(17)$ & $29(83)$ & & Positive & $2(18)$ & $9(82)$ & \\
\hline Depressed & $6(13)$ & $42(87)$ & & Negative & $10(14)$ & $62(96)$ & \\
\hline Tumor size & & & 0.19 & Horizontal margin & & & $<0.01$ \\
\hline$<30 \mathrm{~mm}$ & $5(10)$ & $44(90)$ & & Positive & $6(67)$ & $3(33)$ & \\
\hline$>30 \mathrm{~mm}$ & $7(21)$ & $27(79)$ & & Negative & $6(8)$ & $68(92)$ & \\
\hline Depth & & & 0.43 & Vertical margin & & & $<0.01$ \\
\hline$<\mathrm{SM} 2$ & $3(10)$ & $26(90)$ & & Positive & $6(35)$ & $11(65)$ & \\
\hline$>$ SM2 & $9(17)$ & $45(83)$ & & Negative & $6(9)$ & $60(91)$ & \\
\hline Differentiation & & & 0.11 & ESD margin & & & $<0.01$ \\
\hline Differentiated & $10(19)$ & $42(81)$ & & Positive & $9(41)$ & $13(59)$ & \\
\hline Undifferentiated or mixed & $2(6)$ & $29(94)$ & & Negative & $3(5)$ & $58(95)$ & \\
\hline
\end{tabular}

RC: Residual cancer; UL: ulceration.

Table III. Cases with negative margins in ESD and cancer positive in the surgical specimen.

\begin{tabular}{|c|c|c|c|c|c|c|c|c|c|c|c|}
\hline Case & Gender & $\begin{array}{l}\text { Age } \\
\text { (years) }\end{array}$ & $\begin{array}{l}\text { Surgical } \\
\text { procedure }\end{array}$ & Location & $\begin{array}{l}\text { Morphological } \\
\text { type }\end{array}$ & $\begin{array}{c}\text { Tumor } \\
\text { size }(\mathrm{mm})\end{array}$ & Depth & $\begin{array}{l}\text { Histologic } \\
\text { type }\end{array}$ & $\mathrm{UL}$ & ly & $\mathrm{v}$ \\
\hline 1 & Male & 71 & LADG & M & IIa+IIc & 50 & SM2 & tub2 & - & + & - \\
\hline 2 & Male & 80 & LADG & M & IIa & 37 & SM2 & tub1 & - & + & - \\
\hline 3 & Male & 76 & LAPG & $\mathrm{U}$ & IIc & 12 & SM2 & tub1 & - & - & - \\
\hline
\end{tabular}

M: Middle; U: upper; tub1: tubular adenocarcinoma 1 (well differentiated adenocarcinoma); tub2: tubular adenocarcinoma 2 (moderately differentiated adenocarcinoma); UL: ulceration; ly: lymphatic invasion; v: vascular invasion.

without ulceration, $p=0.3793), 18 \%$ in cases with lymphatic invasion $(8 \%$ in cases without lymphatic invasion, $p=0.1631)$, and $27 \%$ in cases with vascular invasion $(10 \%$ in cases without vascular invasion, $p=0.0958)$. However, there were no significantly increased risks for LN metastasis associated with these factors (Table IV).

\section{Discussion}

Among patients who underwent non-curative ESD without additional gastrectomy, 7.3 to $11.9 \%$ of patients experienced local recurrence or distant metastases, and more than one third died of gastric cancer recurrence (17-19). There are some reports indicating that additional gastrectomy after non-curative ESD is beneficial $(5,6,17,19,20)$, especially in cases with sm2 invasion or deeper $(19,20)$ and with lymphovascular invasion $(5,20)$. In the current study, although we did not compare the long-term outcomes between the patients who underwent additional gastrectomy after non-curative ESD and the patients without additional surgery, no patient who underwent additional gastrectomy had experienced recurrence. This may suggest the efficiency of additional gastrectomy in patients with non-curative ESD. However, it is unknown whether additional gastrectomy including ESD scar plus lymph node dissection is truly unavoidable for all cases after non-curative ESD.

In the current study, $\mathrm{RC}$ in the ulcer scar of surgical specimen existed in 3 patients with negative margins in ESD specimens, and the tumor depth in all 3 cases was deeper than sm2. The local recurrence rates after complete resection by ESD have been reported to be $0-0.66 \%$ and the rate of local recurrence was significantly higher in patients 
Table IV. Clinicopathological background with or without lymph node metastasis.

\begin{tabular}{|c|c|c|c|c|c|c|c|}
\hline & $\begin{array}{c}\mathrm{pN}(+) \\
\mathrm{n}=10(\%)\end{array}$ & $\begin{array}{c}\mathrm{pN}(-) \\
\mathrm{n}=73(\%)\end{array}$ & $p$-Value & & $\begin{array}{c}\mathrm{pN}(+) \\
\mathrm{n}=10(\%)\end{array}$ & $\begin{array}{c}\mathrm{pN}(-) \\
\mathrm{n}=73(\%)\end{array}$ & $p$-Value \\
\hline Age (years) & & & 0.53 & $\mathrm{UL}$ & & & 0.38 \\
\hline$<70$ & $6(14)$ & $36(86)$ & & Positive & $6(15)$ & $33(85)$ & \\
\hline$>70$ & $4(10)$ & $37(90)$ & & Negative & $4(9)$ & $40(91)$ & \\
\hline Gender & & & 0.21 & Lymphatic invasion & & & 0.16 \\
\hline Male & $6(10)$ & $57(90)$ & & Positive & $6(18)$ & $27(82)$ & \\
\hline Female & $4(20)$ & $16(80)$ & & Negative & $4(8)$ & $46(92)$ & \\
\hline Macroscopic type & & & 0.06 & Vascular invasion & & & 0.10 \\
\hline Non-depressed & $7(20)$ & $28(80)$ & & Positive & $3(27)$ & $8(73)$ & \\
\hline Depressed & $3(6)$ & $45(94)$ & & Negative & $7(10)$ & $65(90)$ & \\
\hline Tumor size & & & 0.54 & Horizontal margin & & & 0.32 \\
\hline$<30 \mathrm{~mm}$ & $5(10)$ & $44(90)$ & & Positive & $2(22)$ & $7(78)$ & \\
\hline$>30 \mathrm{~mm}$ & $5(15)$ & $29(85)$ & & Negative & $8(11)$ & $66(89)$ & \\
\hline Depth & & & 0.29 & Vertical margin & & & 0.38 \\
\hline$<\mathrm{SM} 2$ & $2(7)$ & $27(93)$ & & Positive & $1(6)$ & $16(94)$ & \\
\hline$>\mathrm{SM} 2$ & $8(15)$ & $46(85)$ & & Negative & $9(14)$ & $57(86)$ & \\
\hline Differentiation & & & 0.38 & ESD margin & & & 0.62 \\
\hline Differentiated & $5(10)$ & $47(90)$ & & Positive & $2(9)$ & $20(91)$ & \\
\hline Undifferentiated or mixed & $5(16)$ & $26(84)$ & & Negative & $8(13)$ & $53(87)$ & \\
\hline
\end{tabular}

UL: Ulceration.

with expanded indication lesions (11-14). Toyokawa et al. reported the possibility of spreading of the residual cancer from the vessels or their accumulation within the vessels due to vascular stasis in cases with negative margins in ESD and cancer positive in the surgical specimens (15). Park et al. also mentioned the possibility that remnant malignant cells might remain on the negative resection margin since the coagulated portion of the resection margin could not be assessed accurately (13). In our cases, the RC within the sm2 layer where lymphovascular vessels are rich may spread out from the extent of ESD. Therefore, cases with submucosal invasion deeper than $\mathrm{sm} 2$ required additional gastrectomy including the ESD scar even though the margin after ESD was pathologically negative. In other words, there is a possibility that $\mathrm{LN}$ dissection plus gastrectomy without ESD scar or with partial resection of ESD scar is adequate additional surgery for tumor with less than sm1 invasion when the pathological margin is negative after ESD. This fact indicates that surgeons can avoid total gastrectomy for complete resection of ESD scar with negative margin, especially for patients with high-risk of complications.

In the current study, the rate of LN metastasis was $12.0 \%$ in patients who underwent additional gastrectomy following non-curative ESD, which was a bit higher than previous reports $(5.7-9.3 \%)(2,5,6,18)$. Risk factors for $\mathrm{LN}$ metastasis in EGC identified from a large surgical study included large tumor size, submucosal deep tumor invasion, undifferentiated histology, lymphovascular invasion, and ulceration $(2,9,10)$. In our study, although there was no factor that showed a significant association, LN metastasis increased in cases with an invasion deeper than $\mathrm{sm} 2$, in cases with undifferentiated tumors, and in cases with ulceration. However, the additional lymph node dissection can't be omitted due to more than $5 \%$ of lymph node metastasis in all patients after ESD.

Regarding the optimal extent of LN dissection in the additional gastrectomy after non-curative ESD, there is no consensus or recommendation (2). However, gastrectomy with $\mathrm{D} 1+\mathrm{LN}$ dissection is recommended after non-curative ESD except in patients with a suspected advanced gastric cancer (21). Considering the high possibility of $\mathrm{LN}$ metastasis after non-curative ESD, it is difficult to decrease the extent of LN dissection to D0 or D1.

In conclusion, $\mathrm{LN}$ dissection is essential after non-curative ESD to prevent lymph node recurrence. To prevent local recurrence by RC after ESD, gastrectomy including the ESD scar should be performed not only in cases with a pathological-positive margin in ESD, but also in cases with invasion deeper than $\mathrm{sm} 2$, even though the pathological margin was negative.

\section{Conflicts of Interest}

All Authors have no conflicts of interest associated with this manuscript. 


\section{References}

1 Carter KJ, Schaffer HA and Ritchie WP: Early gastric cancer. Ann Surg 199: 604-909, 1984.

2 Sunagawa H, Kinoshita T, Kaito A, Shibasaki H, Kaneko K, Ochiai A, Ohtsu A and Nishida T: Additional surgery for noncurative resection after endoscopic submucosal dissection for gastric cancer: a retrospective analysis of 200 cases. Surg Today 47: 202-209, 2017.

3 Gotoda T: A large endoscopic resection by endoscopic submucosal dissection procedure for early gastric cancer. Clin Gastroenterol Hepatol 3: S71-73, 2005.

4 Toyokawa T, Inaba T, Omote S, Okamoto A, Miyasaka R, Watanabe K, Izumikawa K, Fujita I, Horii J, Ishikawa S, Morikawa T, Murakami T and Tomoda J: Risk factors for noncurative resection of early gastric neoplasms with endoscopic submucosal dissection: Analysis of 1,123 lesions. Exp Ther Med 9: 1209-1214, 2015.

5 Kawata N, Kakushima N, Takizawa K, Tanaka M, Makuuchi R, Tokunaga M, Tanizawa Y, Bando E, Kawamura T, Sugino T, Kusafuka K, Shimoda T, Nakajima T, Terashima M and Ono H: Risk factors for lymph node metastasis and long-term outcomes of patients with early gastric cancer after non-curative endoscopic submucosal dissection. Surg Endosc 31: 1607-1616, 2017.

6 Kim ER, Lee H, Min BH, Lee JH, Rhee PL, Kim JJ, Kim KM and Kim S: Effect of rescue surgery after non-curative endoscopic resection of early gastric cancer. Br J Surg 102: 1394-1401, 2015.

7 Ohnita $\mathrm{K}$, Isomoto $\mathrm{H}$, Shikuwa $\mathrm{S}$, Yajima $\mathrm{H}$, Minami $\mathrm{H}$, Matsushima K, Akazawa Y, Yamaguchi N, Fukuda E, Nishiyama $\mathrm{H}$, Takeshima F and Nakao K: Early and long-term outcomes of endoscopic submucosal dissection for early gastric cancer in a large patient series. Exp Ther Med 7: 594-598, 2014.

8 Gotoda $\mathrm{T}$, Yamamoto $\mathrm{H}$ and Soetikno RM: Endoscopic submucosal dissection of early gastric cancer. J Gastroenterol 41: 929-942, 2006.

9 Haruta H, Hosoya Y, Sakuma K, Shibusawa H, Satoh K, Yamamoto H, Tanaka A, Niki T, Sugano K and Yasuda Y: Clinicopathological study of lymph-node metastasis in 1,389 patients with early gastric cancer: assessment of indications for endoscopic resection. J Dig Dis 9: 213-218, 2008.

10 Barreto SG and Windsor JA: Redefining early gastric cancer. Surg Endosc 30: 24-37, 2016.

11 Takenaka R, Kawahara Y, Okada H, Hori K, Inoue M, Kawano S, Tanioka D, Tsuzuki T, Yagi S, Kato J, Uemura M, Ohara N, Yoshino T, Imagawa A, Fujiki S, Takata R and Yamamoto K: Risk factors associated with local recurrence of early gastric cancers after endoscopic submucosal dissection. Gastrointest Endosc 68: 887-894, 2008.

12 Isomoto H, Shikuwa S, Yamaguchi N, Fukuda E, Ikeda K, Nishiyama H, Ohnita K, Mizuta Y, Shiozawa J and Kohno S: Endoscopic submucosal dissection for early gastric cancer: a large-scale feasibility study. Gut 58: 331-336, 2009.
13 Park JC, Lee SK, Seo JH, Kim YJ, Chung H, Shin SK and Lee YC: Predictive factors for local recurrence after endoscopic resection for early gastric cancer: long-term clinical outcome in a single-center experience. Surg Endosc 24: 2842-2849, 2010.

14 Tanabe S, Ishido K, Matsumoto T, Kosaka T, Oda I, Suzuki H, Fujisaki J, Ono H, Kawata N, Oyama T, Takahashi A, Doyama H, Kobayashi M, Uedo N, Hamada K, Toyonaga T, Kawara F, Tanaka S and Yoshifuku Y: Long-term outcomes of endoscopic submucosal dissection for early gastric cancer: a multicenter collaborative study. Gastric Cancer 20: 45-52, 2017.

15 Toyokawa T, Ohira M, Tanaka H, Minamino H, Sakurai K, Nagami Y, Kubo N, Yamamoto A, Sano K, Muguruma K, Tominaga K, Nebiki H, Yamashita Y, Arakawa T and Hirakawa $\mathrm{K}$ : Optimal management for patients not meeting the inclusion criteria after endoscopic submucosal dissection for gastric cancer. Surg Endosc 30: 2404-2414, 2016.

16 Japanese Gastric Cancer Association: Japanese gastric cancer treatment guidelines 2014 (ver. 4). Gastric Cancer 20: 1-19, 2017.

17 Eom BW, Kim YI, Kim KH, Yoon HM, Cho SJ, Lee JY, Kim CG, Kook MC, Kim YW, Nam BH, Ryu KW and Choi IJ: Survival benefit of additional surgery after noncurative endoscopic resection in patients with early gastric cancer. Gastrointest Endosc 85: 155-163.e3, 2017.

18 Oda I, Gotoda T, Sasako M, Sano T, Katai H, Fukagawa T, Shimoda T, Emura F and Saito D: Treatment strategy after noncurative endoscopic resection of early gastric cancer. Br J Surg 95: 1495-1500, 2008.

19 Choi JY, Jeon SW, Cho KB, Park KS, Kim ES, Park CK, Chung YJ, Kwon JG, Jung JT, Kim EY, Kim KO, Jang BI, Lee SH, Park JB and Yang CH: Non-curative endoscopic resection does not always lead to grave outcomes in submucosal invasive early gastric cancer. Surg Endosc 29: 1842-1849, 2015.

20 Han JP, Hong SJ, Kim HK, Lee YN, Lee TH, Ko BM and Cho JY: Risk stratification and management of non-curative resection after endoscopic submucosal dissection for early gastric cancer. Surg Endosc 30: 184-189, 2016.

21 Son SY, Park JY, Ryu KW, Eom BW, Yoon HM, Cho SJ, Lee JY, Kim CG, Lee JH, Kook MC, Choi IJ and Kim YW: The risk factors for lymph node metastasis in early gastric cancer patients who underwent endoscopic resection: is the minimal lymph node dissection applicable? Surg Endosc 27: 3247-3253, 2013. 